\title{
1. Introduction: Regulating finance in Europe: policy effects and political accountability
}

\section{Adrienne Héritier and Johannes Karremans}

\subsection{INTRODUCTION}

In the aftermath of the global financial crisis, international financial markets were subject to a new wave of regulations on both sides of the Atlantic (Helleiner and Pagliari 2011). At the onset following the 2009 G20 Pittsburgh Summit, the intention was to enhance global regulations and initial efforts were largely driven by the aim to strengthen supranational rulemaking. In Europe, this would result in a strengthening of European competencies in the regulation of financial markets, and in particular those of the European Commission and the European Securities and Markets Authority (ESMA). Recent studies, however, have shown that despite extensive European regulatory reforms, national authorities still maintain a considerable degree of de facto regulatory power (Helleiner 2014). More precisely, the recent regulatory reforms of European financial market regulation have resulted in different patterns of centralised, de-centralised and even fragmented rulemaking, with regulatory standards mostly set at the European level and effective market supervision carried out at the member-state level (Héritier and Schoeller 2020). In parallel, as always in financial regulation, through self-regulation, co-regulation with regulators and lobbying by interest groups, private actors have provided substantial inputs to the content of European regulations (Helleiner et al. 2018; Karremans and Héritier 2020; Smolenska et al. 2020).

Given this variegated picture of the structure of financial regulation, the new governance of financial markets in Europe raises new questions about the locus and mechanisms with which decision-makers and supervisors are held accountable for the substance of their decisions in the light of public interest and the specific objectives of legislative provisions (see, for example, Mattli 2019; Pistor 2019). More particularly, this volume raises the questions of who 
is accountable to whom in the regulation of financial markets in Europe and how accountability mechanisms are linked with actual policy effects.

In trying to answer these questions, we build on a distinction between procedural and substantive accountability, with the former referring to the formal mechanisms with which key actors are held accountable and the latter to the policy scope and policy effects of these mechanisms. On the basis of this distinction, in this volume we investigate both the political accountability channels that are available vis-à-vis regulators (public and private) in the case of important financial legislative measures in post-crisis Europe and the substantive issues on which key actors in the governance of financial markets are held accountable. In addition, the various chapters also provide insights into the regularity with which accountability channels are used for which types of policy issues, the tension between the regulators' autonomy in performing their tasks and holding them accountable, and the policy impact of the use of accountability mechanisms.

More specifically, with regard to the procedural aspects of accountability, the volume deals with the following questions:

- Which are the political accountability channels that are available vis-à-vis public or private regulators in the case of important financial legislative measures in post-crisis Europe?

- Are the accountability mechanisms clear and straightforward or is there a multiplicity of channels that are linked and therefore may be confusing for the actors which wish to use them?

- Who are accountability channels used by? Are they most frequently used by powerful market actors defending their particular interests or public interest groups pursuing social and environmental sustainability goals?

In addition, linking substantive policy aspects or substantive accountability with procedural accountability, the chapters in this volume also aim to shed light on the following issues:

- How does the use of these accountability channels link up with policy effects with respect to these measures?

- Which types of issues are prone to being challenged through accountability channels? Are redistributive issues more prone to being challenged than win-win issues?

- Are accountability channels used on a regular basis or only when the effects of regulation prove to be dissatisfactory?

- Do well functioning accountability mechanisms help to improve policy effects? 
Investigating these questions entails exploring the actors, institutional rules, modalities, scope and policy effects of accountability mechanisms. In raising these questions regarding the political accountability/policy effects link, several analytical conceptual distinctions need to be made, first addressing the political accountability aspect and then linking political accountability to the policy effects aspect.

Throughout this volume, the term 'accountability' is understood as the process in which an actor is required to provide information about its actions and decisions to an audience. The process can have political, legal and administrative aspects: political in the sense of responsibility for collective binding decisions, legal in the sense of potential sanctions that may be applied as a consequence of misconduct and administrative in the sense of sharing information with relevant stakeholders. In this volume, we seek to analyse accountability in the governance of financial markets by taking into account all these aspects. The contributions to the volume will therefore provide an overview and analysis of the actors, institutional rules, modalities, scope and policy effects of accountability mechanisms. We focus on political accountability in the sense of agents being accountable to political bodies and the executive bodies charged by political actors. We focus on legal accountability only if in accountability conflicts political actors turn to courts in order to seek dispute resolution.

\subsection{ACCOUNTABILITY AND ITS DIFFERENT MANIFESTATIONS}

Accountability in European economic governance is the subject of an increasing volume of scholarship. The 2010s was a decade of extensive reforms across the whole sphere of European economic governance, as a result of which there has been a substantial relocation of key decision-making responsibilities. The reforms have therefore generated various questions about how these relocations of decision-making responsibilities have been accompanied by appropriate accountability mechanisms (e.g. Dawson 2015; Howarth and Spendzharova 2019; Schmidt 2020). However, in the specific sphere of financial markets our knowledge of who controls whom remains somewhat limited. Therefore, this book brings together different studies on how accountability plays out in the new structures in European financial market regulation.

Accountability is commonly understood as an obligation of an actor/institution which has been given the task of explaining and justifying its actions or decisions against a set of criteria to the actors which have given it the task and/or the public and stakeholders. The agent accepts the responsibility for the manner in which this task is performed (Bovens 2007; Howarth and Spendzharova 2019; Lastra and Shams 2001). Using a vertical-dimension 
principal-agent approach, it comprises a principal delegating a regulatory task to an agent. The principal controls the performance of the delegated task using various sources of information. If the agent does not perform its task to the satisfaction of the principal, it will be dismissed or fined ${ }^{1}$ (Brousseau and Fares 2000; Bendor et al. 2001; Bovens and Schillemans 2014). The public administration literature has added a learning perspective to the definition of accountability, in which the provision of information during accountability processes makes public authorities more effective in fulfilling their mandates and more responsive to the needs and preferences of the principal(s) and their key stakeholders (Bovens et al. 2008). Finally, accountability also has a more legal dimension, in which an actor may be sanctioned by another if it does not fulfil its mandate.

In short, accountability is a mechanism in which one actor $\mathrm{A}$ is required to report on its actions to an actor, a body or a forum of actors B. ${ }^{2}$ The mechanism has a procedural and a substantive aspect (Jeschek et al. 2017). The former is about the formal relationship between actors A and B - in other words, it is about the question of to whom the agent is accountable and the formal means the principal has to control and, if necessary, sanction the agent. The latter is about the scope and the nature of the effects of the delegated regulatory tasks that are subject to accountability mechanisms. In this volume, we aim to map both the procedural and substantive aspects of accountability and analyse their interactive effects.

The analyses collected in the volume focus on different levels of financial law-making in the EU, including directives, regulations and the setting of technical standards. The analyses in the empirical chapters explore how procedural and substantive accountability mechanisms change across these different levels. A key expectation is that at different levels there is different involvement of high-level politicians. We expect high-level politicians like the European legislators, i.e., the Council of Ministers, the European Parliament, European Commissioners, or members of national parliaments - to be involved in the shaping of directives and regulations, and - due to a lack of time and expertise - to be less or not at all involved in the specification of technical standards. An important contribution of this volume will therefore be to illustrate how procedural and substantive accountability take place at this latter level, when high-level politicians are not involved but when important collective-binding decisions are still made.

\subsubsection{Procedural Accountability}

A first important task is to map the actors involved in an accountability mechanism. This involves not only identifying which actor is accountable to whom, but also the target group of the regulation related to the accountability mecha- 
nism. The target group consists of the individuals that might be affected when actor A fulfils its mandate (actor A being the entity that is being held accountable by an actor B). A first important distinction to be made is between mono and plural accountability channels (see also Koppell 2005). In other words: is an agent held accountable by one or two bodies or by several bodies? Second, it is important to distinguish between accountability streams involving only public actors and ones involving both public and private actors (Scott 2000). Depending on the two scenarios, accountability may take different forms.

In systems of public governance, accountability may take the form of a vertical or a horizontal stream. In the vertical stream of accountability, formal power relations follow a principal-agent model in which a principal delegates a regulatory task to an agent and the performance of the delegated task is evaluated on the basis of various sources of information. If the agent does not perform its task to the satisfaction of the principal, the agent may be dismissed or fined (Brousseau and Fares 2000; Bendor et al. 2001; Bovens and Schillemans 2014). In the context of European financial regulation, the European legislators may, for example, delegate a task to ESMA and ESMA in turn to the national competent authorities (NCAs) for task performance and hold the latter accountable.

In a horizontal stream of political accountability, equal formal power is vested in several actors. In European governance, for instance, horizontal accountability happens when the Commission reports to the European Parliament about the state of affairs of a particular policy. Another example is when member states hold each other accountable in sectoral councils when mutually observing task performance in member states (Héritier 2003: 828). Horizontal accountability is therefore about whether actor A and actor B are at the same level in a given governance hierarchy. In the context of European governance - in which the governance structure is complex and interlinked and constantly subject to modifications - the distinction between horizontal and vertical accountability may not always be as clear cut. In this sense, exploring the form that accountability de facto takes can be elucidating with regard to, for example, the relationship between national and supranational public authorities.

As anticipated, the governance of financial markets is not limited to the responsibilities of public authorities but often involves various forms of public-private collaboration. Private organisations may, for example, perform systemic functions in the financial market and may therefore be required by public institutions to report on their actions. An example is the crucial role that central counterparties (CCPs) play in the post-crisis governance of financial markets, as they are responsible for clearing a large share of financial transactions (Bulfone and Smoleńska 2020). Another form of public-private collaboration is when public authorities structurally seek policy advice from 
private actors, which consequently have a comparative advantage in being able to advocate their preferred policies (Bouwen 2004). Furthermore, certain areas of financial markets may at times be officially recognised to be privately self-regulated, under the condition that they comply with certain basic publicly set regulatory criteria. We characterise these forms of accountability as hybrid, i.e., accountability mechanisms involving streams of information between public and private actors. These hybrid streams may sometimes feature vertical or horizontal characteristics, in the sense that in some situations the private actor may be the agent and the public authority the principal, while in other cases the two actors may have an equal power relationship.

The prominent role of private organisations in the governance of financial markets raises various questions about whether accountability mechanisms are in place and whether they ensure that, for example, public interests are safeguarded, given the interests and actions of the financial industry. Focusing on the public/private aspect of accountability mechanisms, we analyse how private actors engaged in self-regulation are held accountable by public bodies or by private stakeholders This may occur both at the level of formal subordination/superordination competences or on the basis of informal accountability mechanisms $^{3}$ (Scott 2000). When several public and private regulators are responsible for task performance in a fragmented field of regulation, they may be linked in a complex network of accountability mechanisms. The question then arises of how these modes of 'extended accountability' in regulatory networks are linked to the traditional hierarchical forms of public accountability mechanisms.

In the context of transnational financial regulation there are many non-state or private actors engaged in self-regulation or co-regulation with state actors (Karremans and Héritier 2020) which in their transnational regulatory activities escape the vertical control of state actors when holding them accountable (Black and Rouch 2008). This raises complex problems like how to use accountability mechanisms in such a way as to challenge the effects of regulation. Another important conceptual question regarding procedural accountability refers to the modes or instruments of control used when holding agents accountable. Are these controls of an ex-ante or ex-post nature? Moreover, are the accountability channels of an open or a selective nature (Dawson and Maricut-Akbik 2019)?

A certain regulators' dilemma of delegation needs to be mentioned when talking about procedural and substantive accountability. Strict control mechanisms through accountability channels to some extent question the independent task performance by the agent. As mentioned above, the principal-agent approach assumes that the delegation of a task to an agent occurs because the principal does not have the expertise to perform the task in question and therefore delegates it to an agent with the corresponding expertise. The agent 
accordingly needs a certain degree of independence to make regulatory decisions using its expertise. This is underlined by the 'political credibility' motive of delegation (Moe 1990). It assumes that delegation takes place because the task performance should be politically credible, i.e., protected from changes in the political majority of governments. In other words, the agent needs to enjoy a certain independence from governments, which may be jeopardised by strong accountability claims. Hence the control mechanisms available in the different accountability channels need to strike a delicate balance between allowing for accountability of principals and target groups on the one hand, and guaranteeing the agent the independence to decide according to its expertise on the other.

The different procedural relationships described and the different actor configurations and modes of control linked to them have different implications for the target groups of a regulation. A procedural description of accountability channels is important in order to know whether there are possible channels to hold decision-makers to account if the target groups of regulation wish to react to regulatory decisions. This becomes politically most relevant if the objects of regulation are discontented with the outcome of the implementation of the regulation. Consequently, it also becomes important to understand whether and how different configurations of accountability channels and modes of accountability in different power relationships are linked with specific contents of regulatory decisions.

\subsubsection{Substantive Accountability}

Vast reliance on private expertise is a typical feature of financial market regulation, which creates transparency problems (Morgan 2009). Financial market transactions in their functioning and their regulation are not easily accessible by the wider public and the target groups of regulation. Consequently, financial market regulation is hard to grasp in its technological and economic complexity. The recent regulatory reform therefore not only raises questions with regard to who is accountable to whom but also with regard to which types of regulatory policies are actually being challenged or can be challenged through accountability channels. From the literature on the relationship between public authorities and business organisations, we know that the former have incentives to curb the interests of the latter only with regard to themes that receive much public attention (Culpepper 2011, 2016). Increasing public oversight of financial markets was an issue of high saliency in the aftermath of the global financial crisis of 2008. At the same time, the regulatory initiatives of the 2010s were technically highly complex and therefore received relatively little attention in public debates. 
In this volume we therefore also engage with the challenge of determining the substantive policy scope for which actors are held accountable, asking the following questions. How do these accountability channels link with policy effects resulting from these measures? Are accountability channels used on a regular basis or only when the effects of regulation prove to be dissatisfactory? Which types of regulatory/policy effects are particularly prone to be challenged in accountability channels? And finally, does the use of accountability channels contribute to the improvement of regulatory decisions?

First, a word of caveat is in order. Financial market transactions in their functioning and their regulation are not easily accessible by the wider public and the target groups of regulation. In other words, financial market regulation is hard to grasp in its technological and economic complexity and in the worldwide interlinkedness of financial transactions and decisions by market players and regulators. The important overall question of the extent to which the regulation of financial markets serves the real economy and to what extent and how regulators are held accountable for this is clearly beyond what can be achieved in the context of this volume. Neither are we studying the overall effect of financial regulation in guaranteeing the system stability of financial markets and the possible channels of accountability that can be used if financial regulation fails to guarantee this.

Instead, we are pursuing a much more modest aim and focus on individual important pieces of European financial market regulation under MiFID II and CMU under the condition of informational accessibility (Héritier and Schoeller 2020). We first ask which types of regulatory policies are most likely to be challenged through accountability channels? Both MiFID II and CMU largely reshaped the governance of financial markets in the EU and therefore are relatively salient in public debates. At the same time, they also involve the regulation of many different technical aspects of the financial markets. Therefore, they allow us to explore the different levels of financial law-making in the EU, including directives, regulations and the setting of technical standards.

To expect a reaction from the addressees of a regulatory decision we must assume that they have enough information about the content and the effect of a regulatory decision. This content has to be salient in their eyes. In other words, it must have caught the public's attention. A regulatory decision catches the attention of the public if it is easy to understand. We add to this precondition that the regulatory decision and its effect have to be controversial in the eyes of the addressees in order to trigger a wish to mobilise accountability mechanisms. Regarding the controversial nature of regulatory decisions, we distinguish between redistributive and win-win decisions. This distinction is based on the literature on the 'policies determine politics' argument introduced by Theodore Lowi (Windhoff-Héritier 1987). This argument is that the features of a policy issue are linked to a specific political conflict or the 
absence of political conflicts. The basic argument is that redistributive issues that imply a redistribution between haves and have-nots or winners and losers are unavoidably linked to political cleavages in the political arena because the groups meant to pay for those who win will oppose such measures. By contrast win-win issues are decisions from which all groups benefit. Therefore, they support such measures in the political arena in a consensual decision-making process. Our argument here is that we expect that redistributive regulatory decisions which are salient will result in controversial debate in the political arena and if adopted and implemented will tend to mobilise the use of accountability channels by the losers from the policy measure.

The second question we raise linking policies with accountability channels is whether the use of accountability channels leads to an improvement of regulatory decisions as measured by the objectives defined in the specific measures. Answering this question implies a comparison of policy effects before and after accountability channels have been mobilised. This evaluative question means that we have to control for other factors which may have influenced the policy outcomes besides the mobilising of accountability channels in the face of discontent with policy results (Hellstern and Wollmann 2013).

\subsection{STRUCTURE OF THE VOLUME}

By joining both procedural and substantive accountability perspectives, this book aims to identify the mechanisms with which, in the current governance of financial market regulation, regulators are held accountable with regard to how their decisions live up to the mandate to increase market transparency, reduce rent-seeking by intermediaries (brokers/dealers), avoid micro-fraud and increase system stability. It seeks to understand how regulators' (formal and informal) power relationships and modes of control affect fulfilment of their mandate, i.e., policy effects and how the responsible actors are held accountable for them. In doing so, the contributions also provide evidence of the extent to which public authorities have the power and instruments to curb the influence of powerful private actors. In addition, the book aims to sketch a picture of how in the governance of financial markets the provision of information impacts on actors' fulfilment of their mandate, expecting that the provision of information gives rise to a mutual learning process that eventually improves the performance of the actor that is being held accountable.

The empirical chapters focus on specific cases and have a similar general structure, consisting of:

- a specification of the actors in the accountability mechanism 
- a definition of their power relationship (vertical, horizontal or publicprivate) and the modes of control (e.g. ex-ante/ex-post), open/selective, type of sanctions)

- a description of the overall configuration of the linked accountability channels

- a description of the presentation of complex technical measures, and an assessment of the frequency of calling for accountability in different issue areas (redistributive or win-win issues)

- an assessment of the policy effects of the use of accountability mechanism

Following this structure, each chapter provides its own answers to the questions raised in the introduction. The individual chapters focus on a wide range of aspects of the governance of financial markets and cover a variety of policy areas and diverse configurations of actors.

In Chapter 2, Johannes Karremans and Magnus Schoeller look at the accountability mechanisms and their effects in the governance of high-frequency trading (HFT). With the introduction of MiFID II, the EU has expanded its regulatory competences to the previously unregulated area of algorithmic trading, including HFT. This extension of the EU's regulatory competences was part of a series of European regulatory measures that were intended to respond to the public call for more oversight of financial markets after the 2008 crisis. The regulation of HFT therefore constitutes a case of extension of public regulation that is driven by public interest but at the same time touches on the interests of private stakeholders and large financial firms. In addition, the regulation of HFT also represents a new configuration of distribution of regulatory competences between the national and European levels. The chapter therefore first explores to whom decision-makers were accountable during the decision-making phase by analysing the hearings that the European Commission held with the European Parliament and interest groups during this phase. Second, it explores the accountability mechanisms with which the implementation and application of the new rules has been ensured by mapping the arenas and mechanisms with which the European and national authorities responsible for implementation are held accountable by the relevant stakeholders.

In Chapter 3 Promitheas Peridis and Adrienne Héritier analyse whether and what type of accountability mechanisms facilitate the enactment of a specific policy aim of MiFID II, namely the unbundling of research costs. The prescription to unbundle research costs under MiFID II aims at limiting rent-seeking in financial trading by intermediaries, i.e., investment banks. Investors give capital to fund managers, who in turn rely on asset managers as brokers/ dealers, such as large investment banks as intermediaries, to invest the funds for a fee. In order to reduce this structural dependency of fund managers on 
asset managers, MiFID II requires asset managers to explicitly divide the costs of research and investment and declare them openly. Regarding the question of whether the measure has so far been successful, there is some empirical evidence that the commission fees of asset managers and the number of brokers have gone down since the entry into force of the regulation. However, there have also been unintended structural effects in the industry. Market research firms have closed down and access to research by medium and little capitalised firms has become more difficult, whereas large banks can impose additional costs for research (i.e., lower commission fees) more easily. In view of the benefits and losses of the measure, the chapter explores in detail the available accountability mechanisms, how they are used and what effects they produce.

Moving on to the problem of the systemic importance of certain private actors, in Chapter 4 Agnieszka Smoleńska and Adrienne Héritier analyse the accountability mechanisms to which central counterparties (CCPs) are subject under the European Market Infrastructure Regulation (EMIR). In the aftermath of the great financial crisis, regulation of derivative transactions became one of the main tenets of the new financial stability regulation. As a result, in derivative contracts CCPs became the buyer for every seller and the seller for every buyer and turned into central nodes in the financial system with an ever-increasing number of transactions being centrally cleared. As their systemic importance continued to expand, so did the regulation of their activity. Following the introduction of EMIR in 2012 and its most recent reform enacted in 2019, a bespoke regime of prudential oversight was created. The chapter argues and empirically shows that hand-in-hand with their growing importance, regulation of CCPs at the international, European and national levels became more and more dense. In order to allow for the calling for accountability of the multiple types of regulators which went along with regulatory provisions, a multitude of accountability channels were created that show features of centralisation, decentralisation and even fragmentation. In response, attempts were made at the European level to contain decentralisation and fragmentation in order to ensure that the use of accountability channels by all the actors involved allows for an improvement of regulation. The chapter also shows that the use of accountability mechanisms is particularly pronounced if redistributive issues creating a cleavage between winners and losers from a policy are at stake, in particular in the question of a level playing field between EU CCPs and third-country CCPs and in the case of a possible CCP failure.

In Chapter 5, Joseph Ganderson explores another aspect of accountability between public and private actors, namely when public regulators need to rely on the expertise of the private sector. More precisely, the chapter explores the mechanisms with which public and private actors have collaborated to improve regulation in financial markets and raises the question of who refer- 
ees this improvement. Innovation in banking and finance has long limited the capacity of international regulatory cooperation, creating incentives for states to competitively deregulate or 'race to the bottom'. However, the post-crisis wave of fragmented disruptive financial innovation known as 'Fintech 3.0' has prompted a different trend in regulatory principles and approaches. Competition for capital investment has led to a 'race from the bottom' in Fintech regulation, where policymakers facing uncertainty over technological effects have explicitly stated their desire to be regulatory standard setters with the hope of establishing path-setting cost and comparative advantages. This has manifested in so-called 'innovation facilitators'; units operated by regulators with a remit to closely collaborate with innovators, simultaneously developing new regulations and helping developmental products make it to market. This chapter analyses the implications that this public-private cooperation has had for accountability chains and the attendant principal-agent dynamics in financial regulation. First, it establishes how different facilitator designs have impacted accountability chains among four key sets of actors - policymakers, regulators, innovators and consumers - in the three largest European economies: Germany, France and the UK. Second, it considers the implications of national facilitators for European regulation. Ultimately, the chapter suggests that countries are approaching innovation-stability trade-offs in variable ways using different facilitator models, and that the shape of any pan-European approach is still up for grabs.

Chapter 6 by Agnieszka Smoleńska and Promitheas Peridis studies the accountability mechanisms and their effectiveness in the new EU Benchmarks regime, an example of a hybrid public-private regulatory structure in financial markets. The new EU rules establish a framework governing the provision of benchmarks and the administrators of benchmarks. The benchmarks are indices serving as essential reference points for financial instruments and financial contracts and in the end for the operation of the markets, including commodity markets, foreign exchange markets and sustainable financial investments. The new set of rules has been put in place in response to specific concerns regarding market misconduct following the LIBOR and EURIBOR manipulation scandal in 2016. This scandal made the question of accountability for index-setting a focal point of regulation. The hybrid nature of the regime centred around private entities delivering functions critical for the market implies a multidimensional accountability regime involving both the European and national levels. The authors analyse empirical evidence of market operation effects and map the procedural accountability mechanisms established. How are the private actors, 'the administrators', held accountable for the setting of the benchmarks? They are accountable to the regulators at the national and EU levels and to other market participants through specific rules (governance requirements, regulation of benchmark structuring). The authors 
focus on procedural accountability mechanisms for indices concerning investments at the interstices of financial and societal (environmental) aims and explore them from the perspective of the substantive objectives of regulation.

In Chapter 7, which is the last empirical contribution, Johannes Karremans explores how in the post-crisis framework the EU's regulatory hand has entered a previously privately self-regulated sphere of the market, namely that of OTC derivatives. The chapter explores how accountability mechanisms have changed in this transition from private to hybrid public-private governance and shows that European authorities are still highly dependent on the industry's sectoral expertise. While in the past OTC-derivatives were entirely privately self-regulated by the International Swaps and Derivatives Association (ISDA), in the new European governance ESMA decides whether such derivatives need to be centrally cleared. In making its decisions, ESMA needs to make sure that the factual governance of the OTC-derivatives market is in line with the policy goals of the European Commission of increasing the transparency of financial markets and avoiding systemic risk. At the same time, in setting the technical standards ESMA closely cooperates with the financial industry through ISDA, which therefore has the possibility of keeping large shares of the derivatives market under its private system of governance. This raises the questions of accountability regarding how the decisions on exemptions from clearing obligations are taken, and how these decisions are in line with the original goal of increasing market transparency and reducing the likelihood of systemic risk. The chapter explores these questions through an analysis of documents leading up to decisions on technical standards. The chapter explores the extent to which ESMA has a clear framework for defining which technical standards are to be maintained in order to meet the Commission's original policy goals or whether instead it systematically follows ISDA's policy advice.

In the Conclusion (Chapter 8), Johannes Karremans and Adrienne Héritier reflect on how the empirical contributions shed light on the questions and arguments raised in this volume and outline the main insights of the empirical chapters discussing the analytical questions. Their reflection highlights how much of the action - in terms of exchange of information between regulators and stakeholders - happens through hybrid mechanisms in which public regulators and private stakeholders regularly and intensively collaborate to smoothen the implementation of regulation. The authors find both challenges and opportunities for how these accountability mechanisms impact on the overall democratic legitimacy of the governance of financial markets. On the one hand, hybrid accountability mechanisms give a considerable advantage to business organisations and firms to influence the course of policy as they provide the expertise that regulators often need. At the same time, in some cases these mechanisms also trigger the engagement of multiple actors in efforts to improve the quality of regulation. 


\section{NOTES}

1. In practice, weaker forms of political accountability are widely used when seeking to hold regulatory authorities accountable. They comprise political delegation to an agent and access to information (transparency) in order to control the agent. The sanctioning element is often missing or very weak in terms of its stringency.

2. The distinction between a 'body' and a 'forum of actors' is that a body is an entity taking decisions, whereas a forum is a gathering of actors simply discussing a certain issue.

3. Informal accountability relations are defined as ones not written down and not subject to third-party dispute resolution, i.e., by courts.

\section{REFERENCES}

Bendor, J., Glazer, A. and T.A. Hammond (2001). Theories of delegation. Annual Review of Political Science, 4, 235-269.

Black, J. and D. Rouch (2008). The development of the global markets as rule-makers: engagement and legitimacy. Law and Financial Markets Review, 2(3), 218-233.

Bouwen, P. (2004). Exchanging access goods for access: A comparative study of business lobbying in the European Union institutions. European Journal of Political Research, 43(3), 337-369.

Bovens, M. (2007). Analysing and assessing accountability: A conceptual framework. European Law Journal, 13(4), 447-468.

Bovens, M. and T. Schillemans (2014), Meaningful accountability. In M. Bovens, R.E. Goodin and T. Schillemans (eds), The Oxford Handbook of Public Accountability, Oxford: Oxford University Press, pp. 673-682.

Bovens, M., Schillemans, T. and P. T. Hart (2008). Does public accountability work? An assessment tool. Public Administration, 86(1), 225-242.

Brousseau, E. and M. Fares (2000). Are incomplete contract theory and new institutional economics substitutes or complements? In C. Ménard (ed.), Institutions, Contracts and Organizations: Perspectives from New Institutional Economics, Cheltenham, UK and Northampton, MA, USA: Edward Elgar Publishing, pp. 399-421.

Bulfone, F. and A. Smoleńska (2020). The internal and external centralisation of Capital Markets Union regulatory structures: The case of Central Counterparties. In A. Héritier and M. Schoeller (eds), Governing Finance in Europe, Cheltenham, UK and Northampton, MA, USA: Edward Elgar Publishing, pp. 52-78.

Culpepper, P. (2011). Quiet Politics and Business Power: Corporate Control in Europe and Japan, New York: Cambridge University Press.

Culpepper, P.D. (2016). Capitalism, institutions, and power in the study of business. In O. Fioretos, T.G. Falleti and A. Sheingate (eds), The Oxford Handbook of Historical Institutionalism, Oxford: Oxford University Press, pp. 453-466.

Dawson, M. (2015). The legal and political accountability structure of 'post-crisis' EU economic governance. JCMS: Journal of Common Market Studies, 53(5), 976-993.

Dawson, M. and A. Maricut-Akbik (2019). Procedural and substantive uses of accountability in modern governance: Between payoffs and trade-offs. Paper Workshop 'Theorizing and Assessing Accountability in Post-Crisis EU Economic Governance'. 25.11.2019, European University Institute Florence. 
Helleiner, E. (2014). Towards cooperative decentralization? The post-crisis governance of global OTC derivatives. In T. Porter (Ed.), Transnational Financial Regulation after the Crisis, New York: Routledge, pp. 132-153.

Helleiner, E. and S. Pagliari (2011). The end of an era in international financial regulation? A postcrisis research agenda. International Organization, 65(1), 169-200.

Helleiner, E., Pagliari, S. and I. Spagna (Eds.) (2018). Governing the World's Biggest Market: The Politics of Derivatives Regulation After the 2008 Crisis, Oxford: Oxford University Press.

Hellstern, G.M. and H. Wollmann (Eds.) (2013). Experimentelle PolitikReformstrohfeuer oder Lernstrategie: Bestandsaufnahme und Evaluierung (Vol. 27). Springer-Verlag.

Héritier, A. (2003). Composite democracy in Europe: The role of transparency and access to information. Journal of European Public Policy, 10(5), 814-833.

Héritier, A. and M.G. Schoeller (2020). Governing Finance in Europe: A Centralisation of Rule-making? Cheltenham, UK and Northampton, MA, USA: Edward Elgar Publishing.

Howarth, D. and A. Spendzharova (2019). Accountability in post-crisis Eurozone governance: The tricky case of the European Stability Mechanism. Journal of Common Market Studies, 57(4), 894-911.

Jeschek, H.-H., Weigend, T., Hazard, G. and C. Yeazell (2017). Procedural and Substantive Accountability, Encyclopedia Britannica.

Karremans, J. and A. Héritier (2020). The emergence of transnational hybrid governance: How private risks trigger public intervention'. In A. Héritier and M.G. Schoeller (Eds.), Governing Finance in Europe: A Centralisation of Rule-making? Cheltenham, UK and Northampton, MA, USA: Edward Elgar Publishing, pp. 137-163.

Koppell, J.G.S. (2005). Pathologies of accountability: ICANN and the challenge of 'multiple accountabilities disorder'. Public Administration Review, 65(1), 84-108.

Lastra, R. and H. Shams (2001). Public accountability in the financial sector. In E. Ferran and C. Goodhart (Eds.), Regulating Financial Services and Markets in the 21st Century, Oxford: Hart, pp. 165-187.

Mattli, W. (2019). Darkness by Design, The Hidden Power in Global Capital Markets, Princeton: Princeton University Press.

Moe, T. (1990). Political institutions: The neglected side of the story. Journal of Law, Economics and Organizations, 6, special issue, 213-253.

Morgan, G. (2009). Legitimacy in financial markets: Credit default swaps in the current crisis. Socio-Economic Review, 8(1), 17-45.

Pistor, K. (2019). The Code of Capital: How the Law Creates Wealth and Inequality, Princeton: Princeton University Press.

Schmidt, V.A. (2020). Europe's Crisis of Legitimacy: Governing by Rules and Ruling by Numbers in the Eurozone, Oxford: Oxford University Press.

Scott, C. (2000). Accountability in the regulatory state. Journal of Law and Society, $27(1), 38-60$.

Smolenska, A., Ganderson, J. and A. Héritier (2020). The impacts of technological innovation on regulatory structure: Fintech in post-crisis Europe. In A. Héritier and M.G. Schoeller (Eds.), Governing Finance in Europe: A Centralisation of Rule-making? Cheltenham, UK and Northampton, MA, USA: Edward Elgar Publishing, pp. 164-189.

Windhoff-Héritier, A. (1987). Policy Analyse: Eine Einfuehrung, Campus Studium. 